\title{
Deberes Jurídicos, Teoría del Derecho y Dogmática Penal
}

Alonso formula e intenta solucionar un problema que presenta como "conflicto de deberes jurídico-penales". Utiliza aquí una "noción" de "deber" -que llama "kelseniana"- según la cual "cuando una norma estipula una sanción para la conducta $\neg \mathrm{p}$, entonces existe el deber jurídico de hacer p"1. Esta "noción" es contrapuesta a la que llama "noción estándar". No obstante la terminología empleada, resulta claro que no se trata en realidad de diversas "nociones" de deber. La distinción se refiere, más bien, a dos modos

"Facultad de Derecho y LanCog (Language, Mind, and Cognition) Group, Universidad de Lisboa; y University College, Oxford. Agradezco a Hernán Bouvier haber revisado el texto $\mathrm{y}$ corregido mi castellano. diferentes de "formulación positiva" (de "positivización") de deberes jurídicos. Un deber es formulado "del modo estándar" si está "explícitamente" ${ }^{1}$ Cf. pág. 22. 
formulado en el material legislado. Un ejemplo de deber formulado "del modo estándar" es el de una norma -que Alonso llama "primaria"- que "enlaza una sanción a una determinada conducta":

la norma primaria responde a la noción estándar de deber jurídico [ya que] (la obligación de sancionar es explícitamente formulada $)^{2}$.

Ya un deber formulado "del modo kelseniano" es un deber -"secundario", en esta terminología- que se obtiene "por derivación" a partir de un deber "estándar" de sancionar. La "noción kelseniana", escribe Juan Pablo,

supone la distinción entre norma primaria y norma secundaria. La norma primaria es la que enlaza una sanción a una determinada conducta, mientras que la secundaria estipula cuál el deber jurídico que se deriva de la norma primaria ${ }^{3}$.

Más precisamente, los "deberes" cuyo conflicto Alonso pretende tratar son obtenidos por "derivación kelseniana" a partir de normas "primarias" penales"; y el problema es discutido a partir de un case study particular extraído del derecho penal argentino. Sostiene Alonso que de los artículos 176/3 y 302/1 del Código Penal argentino "emergen", en el "sistema [normativo] del ciudadano" y por "derivación kelseniana", "deberes jurídico penales", y que entre esos deberes hay un "conflicto" al menos para un caso. Su artículo es dedicado a la caracterización de este conflicto y, después, a la discusión de las "reacciones del sistema normativo del juez" "ante la existencia de conflictos de deberes jurídico-penales en el sistema del ciudadano"5.

Resulta evidente, por lo tanto, que la formulación misma de este problema depende de que se acepte que lo que Alonso llama

\footnotetext{
${ }^{2}$ Cf. pág. 25.

${ }^{3}$ Cf. pág. 23.

"Parece ser en este sentido que Alonso habla de "deberes jurídico-penales" (énfasis mío), una vez que no hay razón para suponer que los deberes jurídicos cuya infracción sea penalmente sancionada sean deberes específicamente "penales" en algún otro sentido útil del término.

${ }^{5}$ Cf. pág. 26.

86 - Revista Discusiones No 9
} 
"derivación kelseniana" sea efectivamente un modo de "formulación" de deberes. Alonso no parece tener dudas o hesitaciones al respecto. Sostiene que "a veces los deberes jurídicos se formulan del modo estándar, otras veces del modo kelseniano, y en otras ocasiones de ambos modos". Y sugiere, en general, que en las disposiciones características de "las partes especiales de los Códigos Penales contemporáneos" -en las cuales típicamente se asocia una sanción penal a la descripción de alguna acción u omisión- siempre se obtiene por "derivación kelseniana" el deber de no practicar la acción u omisión correspondiente:

Un ejemplo de formulación kelseniana es el artículo 79 del Código Penal Argentino, que establece la obligación de no cometer homicidio mediante la atribución de una pena privativa de libertad de ocho a veinticinco años a quien lo cometiera ("Se aplicará reclusión o prisión de ocho a veinticinco años al que matare a otro... $)^{6}$.

En este artículo intentaré mostrar que la noción de "derivación kelseniana", sobre la cual está basado todo el trabajo de Juan Pablo Alonso, es insostenible y que -en consecuencia- el problema planteado en "Normas Penales y Conflicto de Deberes" se disuelve $a b$ initio como un falso problema ${ }^{7}$.

En el centro de la tesis de la "derivación" de normas de comportamiento a partir de normas de sanción parece encontrarse una idea que, aunque conspicuamente presente en varios textos de Kelsen, se encuentra relativamente generalizada en la literatura de Teoría del Derecho. Bentham, por ejemplo, escribe que:

\footnotetext{
${ }^{6}$ Cf. pág. 23.

${ }^{7}$ Esto lo entiendo como una crítica dirigida directamente a Alonso, y no a Kelsen - que por cierto, y como sostendré también, nunca defendió en sus escritos esa operación de "derivación" que Alonso ha decidido bautizar (aunque, creo, sin intenciones distorsivas) con el adjetivo "kelseniana" -
} 
by implication, and that a necessary one, the punitory [law] does involve and include the import of the simple imperative law to which it is appended ${ }^{8}$.

\section{Otro ejemplo es Ross:}

if one knows that the courts are directed by these laws to imprison whoever is guilty of manslaughter, then, since imprisonment is a reaction of disapproval and, consequently, a sanction, one knows that it is forbidden to commit manslaughter. This last norm is implied in the first one directed to the courts; logically, therefore, it has no independent existence. [...] At times, those drafting statutes employ the device of formulating a legal rule as a directive to courts, leaving it to the citizen to infer what conduct is required of him. The criminal code is drawn in exactly this way. Nowhere is it stated in so many words that manslaughter is prohibited. The prescription against this and other crimes is, rather, inferred from the appropriate rules of the criminal code which are directed to the judge. [...] Primary norms, logically speaking, contain nothing not already implied in secondary norms, whereas the converse does not hold ${ }^{9}$;

Y en Kelsen, de hecho, uno puede leer pasajes como el siguiente:

Cuando un sistema social, como el orden jurídico, obliga a una conducta en cuanto estatuye para el caso de la conducta opuesta una sanción, cabe describir la situación mediante una proposición que enuncia que, en caso de una determinada conducta, debe producirse una determinada sanción. Con ello ya queda dicho que la conducta que es condición de la sanción se encuentra prohibida, y su contraria es obligatoria. El ser debido de la sanción implica [o "contiene": la expresión

${ }^{8}$ An Introduction to the Principles of Morals and Legislation (J. H. Burns, H. L. A. Hart, eds.), London: The Athlone Press (1970) 303; énfasis mío.

${ }^{9}$ Directives and Norms, London: Routledge \& Kegan Paul (1968) 91-2; énfasis mío. 
original es "schließt... in sich"] en sí mismo el estar prohibida la conducta que es su condición específica y el ser obligatoria la conducta opuesta ${ }^{10}$.

Múltiples cosas podrían decirse acerca de la correcta forma de entender y ubicar estas citas en sus respectivos (y algo diferentes entre sí) contextos teóricos. No me ocuparé de tal tarea. Estos extractos sólo pretenden ilustrar - mediante diferentes formulaciones — la idea según la cual las normas de conducta son en algún sentido "derivables" de las normas de sanción. ¿Cómo se supone, entonces, que opera esta derivación? Consideremos las siguientes dos proposiciones:

(1) Se aplicará reclusión o prisión de ocho a veinticinco años al que matare a otro

(2) Está prohibido matar a otro.

La tesis de la "derivación" parece sostener que la verificación, relativa a un orden jurídico, de una proposición como (1) implica la verdad de una proposición como (2). Pero ¿cómo opera este "pasaje de la 'norma primaria penal' al 'deber jurídico-penal'”?'ic ¿Cuál es el fundamento de la "regla de conversión" de la que habla Alonso?"

Anota Alonso, un tanto equívocamente, y citando a Nino, que la derivación "no es una derivación lógica, sino una derivación por definición del concepto de "deber jurídico""13. Yo creo, sin embargo, y por el contrario, que la idea envuelta en esta noción de "derivación" se relaciona al concepto de pena, o sanción punitiva. Esto es muy claro en los textos de Kelsen. El término "sanción", sostiene Kelsen, puede ser utilizado en dos sentidos. En su "sentido amplísimo", "cabe extender el concepto de sanción a todos los actos coactivos estatuidos por el orden jurídico" 14 . En el "sentido más estricto y restringido" del término, es

\footnotetext{
$\overline{10}$ Teoría Pura del Derecho, 2. ${ }^{a}$ ed. (1960) 39, énfasis mío; utilizo la traducción de Roberto J. Vernengo, Mexico: Universidad Nacional Autónoma (1979).

${ }^{11}$ Cf. pág. 24.

${ }^{12}$ Cf. pág. 23.

${ }^{13}$ Cf. pág. 23, nota 5.

14 Teoría Pura del Derecho, cit., 55.
} 
equivalente al de "pena" ("Strafe"), y refiere a cualquier "perjuicio" o "mal" que tiene que aplicarse "como consecuencia de determinada conducta"15. Ahora bien, en el conocido programa de Kelsen, dirigido a la "reducción" (o "representación") de todo el material normativo de un determinado orden jurídico a "normas de sanción" -o, de modo más preciso, a la forma de "Rechtssätze" declarando "que, bajo determinadas condiciones... deben ejecutarse determinados actos coactivos"16_ el término "sanción" es usado en sentido amplio. Al mismo tiempo, es claro que para Kelsen las normas de conducta cuya "derivación" está aquí en juego deben ser derivadas no de las normas sancionatorias en sentido amplio, sino de las normas sancionatorias stricto sensu:

[T]ampoco todas las normas que estatuyen actos coactivos obligan, sino sólo aquellas que estatuyen el acto coactivo como reacción -es decir, como sanción [en el sentido estricto]- contra determinada conducta humana, obligando, pues, a la conducta contraria ${ }^{17}$.

En este sentido estricto, de hecho, "sanción" resulta correlativa del concepto de "delito" (un tipo de conducta jurídicamente "prohibida"):

Tan pronto aparece el acto coactivo estatuido por el orden jurídico como reacción ante una conducta humana determinada por ese orden, el acto coactivo adquiere el carácter de una sanción [en el sentido estricto], y la conducta humana contra la cual se dirige el acto coactivo, el carácter de un comportamiento prohibido, antijurídico, de una transgresión o delito ${ }^{18}$.

\footnotetext{
15 Teoría Pura del Derecho, cit., 38-39, 52. Hay también un concepto intermedio de sanción, concebida como reacción frente a un delito cuya existencia no haya sido aún debidamente comprobada; la detención in flagrante delicto es un ejemplo. Cf. id., 54 .

${ }^{16}$ Id., 70.

${ }^{17}$ Id., ibid.; énfasis mío.

${ }^{18}$ Id., 48. 
Sin embargo, éste no es el caso en el "sentido amplio":

[L]os actos coactivos estatuidos por el orden jurídico, como consecuencia de otras circunstancias de hecho, no son "sanciones" en el sentido específico de consecuencias de lo ilícito; y los hechos condicionantes, al no ser acciones u omisiones de determinados hombres, determinados por el orden jurídico, no tienen el carácter de actos ilícitos o de delito $^{19}$.

Las normas de sanción en sentido estricto, entonces, y para repetir, son un subconjunto de las normas de sanción en sentido amplio; y la tesis de la "derivación" funciona sólo con las normas de sanción stricto sensu. Es por lo tanto de central importancia no mezclar ambas nociones. La confusión, desafortunadamente, es bastante frecuente. Para el caso, Alonso parece no tener presente está distinción. Así sostiene:

La noción kelseniana de “deber jurídico’ supone la distinción entre norma primaria y norma secundaria. La norma primaria es la que enlaza una sanción a una determinada conducta, mientras que la secundaria estipula cuál es el deber jurídico que se deriva de la norma primaria [...] Kelsen sostiene que los sistemas jurídicos, en tanto órdenes coactivos, sólo se componen de normas primarias, considerando a las normas secundarias como superfluas; afirma, incluso, que las únicas normas jurídicas genuinas son las que estipulan sanciones ${ }^{20}$.

Alonso parece pensar aquí, equivocadamente, que la noción de "norma de sanción" involucrada en las observaciones de Kelsen acerca de las normas de sanción "genuinas" (o "completas", o "independientes": el término original es "vollständige Rechtsnorm") a las cuales todo el material debe ser reducido es la misma noción de norma de sanción "primaria" involucrada en la idea de que las normas de conducta (que, en la terminología de Kelsen se denominan "secundarias") pueden de alguna manera ser "derivadas" de las normas

19 125-6.

${ }^{20}$ Cf. pág. 23. 
de sanción. En este error, no obstante, Alonso se encuentra bien acompañado. Compárese, a este respecto, un pasaje famoso de Hart:

\begin{abstract}
Without recourse to the simple idea that criminal law sets up, in its rules, standards of behaviour to encourage certain types of conduct and discourage others we cannot distinguish a punishment in the form of a fine from a tax on a course of conduct. This indeed is one grave objection to those theories of law which in the interests of simplicity or uniformity obscure the distinction between primary laws setting standards for behaviour and secondary laws specifying what officials must or may do when they are broken. Such theories insist that all legal rules are "really" directions to officials to exact "sanctions" under certain circumstances, e.g. if people kill ${ }^{21}$.
\end{abstract}

Esta se ha tornado una forma bastante común de entender las cosas para quienes insisten en la diferenciación entre normas de conducta y normas de sanción objetando el "reduccionismo" de Kelsen (el cual fue también blanco de ataque de Hart). En la medida en que es presentado como un ataque al proyecto de Kelsen, el argumento no es bueno. Las multas y los impuestos son incomparables. Para Kelsen, se debe jurídicamente un impuesto si la ausencia de pago voluntario constituye una condición de una sanción en sentido estricto. El deber jurídico de pagar un impuesto sería comparable, más bien, con (por ejemplo) el deber de no matar. Sin embargo, el punto de Hart podría ser reformulado como un punto acerca de la diferencia entre delitos y otros tipos de acciones no-delictivas que pueden también constituir una condición de medidas coercitivas jurídicamente prescriptas. Para poder trazar tal diferencia (en la línea del argumento reformulado de Hart) es necesario distinguir entre normas coercitivas punitivas y no punitivas. Y la única forma de hacerlo es concebir a las normas punitivas como entrando en juego cuando "las reglas primarias que establecen estándares de comportamiento" son infringidas. Se trata, en otras palabras, de

${ }^{21}$ Punishment and Responsibility. Essays in the Philosophy of Law, Oxford: Clarendon Press (1968) 7. Cf. también el pasaje similar en El Concepto de Derecho, 2. ${ }^{a}$ ed., Oxford: OUP (1994) 49-50; utilizo la traducción de Genaro R. Carrió, Buenos Aires: Abeledo Perrot (1963). 
concebir las normas punitivas como "secundarias" en un sentido diferente del adjetivo. La noción de punición, sostiene Hart, "involves... an offence or breach of duty in the form of a violation of a rule set up to guide the conduct of ordinary citizens" 22 . La idea subyacente es por tanto que una norma de sanción penal presupone la infracción de una norma prohibitiva. ¿Desacordaría Kelsen? Seguramente no:

[E]l principio de retribución enlaza una conducta conforme con la norma a un premio, y la conducta contraria a la norma con penitencia o con sanción, presuponiendo así una norma que ordena o prohíbe esa conducta, o, una norma que justamente prohíbe esa conducta, enlazándole una sanción [...] ${ }^{23}$

Podemos entonces poner juntos a Hart y Kelsen en cuanto a la cuestión fundamental aquí discutida. Ambos parecen haber sostenido que la posibilidad misma de interpretar una norma determinada como "norma de sanción" (en sentido estricto) depende de la presuposición de un deber cuya infracción es la condición de una sanción. Las normas de sanción punitivas, por tanto, son siempre normas "de segundo orden". Y este es el sentido en que en teoría general del derecho (aunque no en los trabajos de Kelsen, ni el trabajo de Alonso), y también teoría penal, se les llama "secundarias." 24

${ }^{22} \mathrm{El}$ Concepto de Derecho, cit. 50.

${ }^{23}$ Teoría Pura del Derecho, cit., 106, énfasis mío.

${ }^{24}$ Esto se ha tornado la terminología standard desde, creo, la propuesta de Hans Nawiasky's en Allgemeine Rechtslehre als System der rechtlichen Grundbegriffe, 2. ${ }^{a}$ ed., Zürich: Benziger \& Co. (1948) 13-14, 99-105. La dicotomía "primario" / "secundario" se utiliza también para señalar otras distinciones, más o menos emparentadas con la que ahora está en discusión, tanto en el campo de la teoría general del derecho (en Hart, por ejemplo) o en áreas específicas del derecho (en derecho internacional, v.g., o en derecho constitucional). Norberto Bobbio explora esta "selva profunda" en el estudio "Norme Primarie e Norme Secondarie", incluido en los Studi per una Teoria Generale del Diritto, Torino: Giappichelli (1970) 175-183; cf., también, Giacomo Gavazzi, Norme Primarie e Norme Secondarie, Torino: Giappichelli (1967) 3 ss. 
Pero incluso si aceptamos este punto analítico referente al carácter de segundo orden del concepto de sanción punitiva -que ahora asumo por mor del argumento- ies él suficiente para dar sentido a la tesis de la "derivación"? ¿Se sigue que siempre que interpretamos como "sanción" (en el sentido estricto, punitivo) cualquier acto jurídicamente prescripto, necesariamente interpretamos como prohibido el tipo de acción descripta en el antecedente de la norma de sanción?

La respuesta es negativa. Para ver por qué, regresemos a (1) y (2). En (2) es identificada una norma de conducta determinada: una prohibición cuyo contenido es la acción tipo de matar a alguien. Ese contenido coincide con el antecedente de la norma de sanción presente en (1). A primera vista, esta coincidencia puede parecer lógicamente necesaria, y parte de lo que mantiene la tesis de la derivación. No obstante, es una propiedad contingente del ejemplo. La relación entre normas de sanción y normas de conducta no implica la coincidencia entre sus contenidos descriptivos. Es cierto que la distinción teóricojurídica entre "normas de conducta" y "normas de sanción" es tradicionalmente presentada apelando a ejemplos precisamente como los citados. Es también cierto que (1) parece corresponderse con el sentido inmediato de las disposiciones incriminatorias que característicamente se encuentran en la parte especial de un código penal. Pero la norma de sanción propiamente dicha no es por supuesto la norma que podríamos inmediatamente reconstruir a partir de esas oraciones normalmente incluidas en la parte especial de los códigos penales. La norma de sanción más bien incorpora, en su antecedente, múltiples condiciones diferentes y es típicamente reconstruida a partir de una conjunción de expresiones legislativas dispersas en las cuales tales condiciones son establecidas. Este conjunto incluye la descripción del curso de conducta "prohibido", pero tal descripción no extenúa los elementos que pertenecen al conjunto. Por lo tanto (1) será, en el mejor de los casos, una versión resumida o elíptica de una norma de sanción. Si la expandimos debidamente obtendremos como formulación algo como lo siguiente: 
(1') Si alguien mata a otra persona, y p, y $q$, y..., entonces debe ser sancionado con prisión de 8 a 25 años.

Y la idea de Kelsen y Hart acerca del concepto de sanción es sin dudas insuficiente para fundamentar la "derivación" de (2) a partir de (1'). Nos permitirá inferir que alguna norma de conducta prohibitiva es presupuesta por (1'). Pero no nos ayudará a determinar su contenido preciso, para lo cual un criterio suplementario es necesario. La relación entre normas de sanción y normas de conducta sostenida por la tesis de la derivación puede sólo querer decir que las normas de sanción y conducta no son recíprocamente independientes, mas no puede implicar que sus alcances coincidan. En otras palabras, la tesis de la derivación no afirma algo como:

$\left(\mathrm{TD}^{*}\right)$ La existencia de una norma de sanción $S$ necesariamente implica que existe una correspondiente norma de conducta cuyo contenido es coextensivo con el antecedente de $S$;

más bien afirma algo más débil como:

(TD) La existencia de una norma de sanción implica necesariamente que existe alguna norma de conducta,

lo que es tanto como decir que las normas de sanción son necesariamente normas secundarias: que el antecedente de una norma de sanción siempre incluye la infracción de una norma de conducta. Así reconstruida, la tesis de la derivación no está comprometida con ninguna solución en especial de lo que Joseph Raz llama "the problem of the necessary relation between the scope of D[uty-imposing]-laws and sanction-stipulating norms" - a saber, "what is the relation between the scope of a law and a sanction imposing law which warrants the interpretation of the first as a D[uty-imposing] law?'25.

${ }^{25}$ Cf. The Concept of a Legal System, 2nd ed., Oxford: Clarendon Press (1980) 154. La corrección del punto conceptual de Hart y Kelsen parece a su vez ser presupuesta en la formulación que da Raz al problema. 
Es cierto que la distinción que pretendo subrayar no resulta inmediatamente evidente si limitamos nuestra atención a la formulación elíptica de normas de sanción con la cual la tesis de la implicación es tradicionalmente ilustrada. Dado el punto conceptual de Kelsen y Hart, pareciera que estamos autorizados a inferir (2) de (1) y por tanto a inferir una norma de conducta determinada a partir de una norma de sanción determinada. La razón radica obviamente en que el antecedente de (1) incluye la descripción de un curso de conducta como su única condición, haciendo por tanto lógicamente necesario que la misma descripción figure como el contenido de la norma de sanción. Pero esto, como se indicó, es una propiedad contingente o accidental del ejemplo. Aunque usualmente la "tesis de la derivación" sea formulada con ejemplos como el referido, no sería caritativo vincular a sus defensores (Ross incluido) como suscribiendo a (IT*).

Tampoco sería caritativo vincular a Kelsen con ella. La razón para no atribuir a su frecuente uso de las formulaciones elípticas de las normas de sanción más importancia que la de un mero recurso expositivo radica sobretodo en el hecho de que en su análisis ex professo del concepto de "delito" se emplea debidamente un modelo más extendido de norma de sanción. Examinemos este punto con más detalle. "Delito" ("Delikt", o "Unrecht"), sostiene Kelsen, es la conducta opuesta a una conducta prescripta por el orden jurídico. Y una conducta puede considerarse "jurídicamente ordenada" "sólo en la medida en que el comportamiento opuesto es condición de una sanción" (en sentido estricto)": ${ }^{26}$

[L]a acción u omisión determinadas por el orden jurídico, que configura la condición para un acto coactivo estatuido por el derecho, son designadas como "acto ilícito" o "delito", y el acto coactivo, estatuido como consecuencia, es la consecuencia de lo ilícito o sanción. Sólo porque una acción y omisión, determinadas por el orden jurídico, se convierten en condición de un acto coactivo estatuido por el orden jurídico, se las califica de ilicitud o delito ${ }^{27}$.

\footnotetext{
26 Teoría Pura del Derecho, cit., 39.

${ }^{27}$ Id., 125. 

negación”: ${ }^{28}$

El "delito" es así una "condición del derecho y no su

Cuando un orden normativo ordena determinada conducta, sólo en cuanto enlaza a la contraria una sanción, la situación de hecho es esencialmente descrita, en forma completa, por una proposición hipotética (condicional) que enuncia que si se presenta determinada conducta, debe llevarse a cabo determinado acto coactivo. En este enunciado aparece lo ilícito como el antecedente o condición, pero no como negación del derecho ${ }^{29}$.

Ahora bien, dado que la formulación "completa" de la norma que establece una sanción incorpora otras tantas condiciones además de la conducta delictiva, es evidente que se necesita algún criterio plausible que nos permita caracterizar y distinguir, en el conjunto total de condiciones, la condición (o conjunción de condiciones) que constituye el "delito". Para ese propósito es claramente insuficiente decir meramente que el delito es un "acto o una omisión", visto que, como Kelsen mismo observa,

[E]l hecho condicionante [de una sanción]... puede estar compuesto con muy diversas partes integrantes, entre las cuales pueden aparecer otras conductas humanas que no son calificadas de delito, como por ejemplo, el acto legislativo que produjo la norma general que determina el tipo penal, así como el acto judicial, mediante el cual se ha verificado la existencia del hecho delictivo concreto ${ }^{30}$.

Kelsen propone determinar la conducta delictiva diciendo que "el delito es normalmente la conducta de aquel hombre contra el cual, como consecuencia de su propio comportamiento, se dirige el acto coactivo que sirve de sanción" ${ }^{1}$. Pero inmediatamente observa que "esta determinación conceptual de delito, sin embargo, sólo es aceptable

\footnotetext{
${ }^{28}$ Id., ibid.

${ }^{29}$ Id., 128.

${ }^{30}$ Id., ibid.

${ }^{31}$ Id., ibid.
} 
cuando la sanción se dirige contra el delincuente, es decir, contra aquel que mediante su propia conducta ha efectuado el delito", y no abarca casos en los cuales la sanción es dirigida (como puede perfectamente ocurrir) contra otros individuos distintos al autor del delito (contra los parientes, por ejemplo) ${ }^{32}$. Luego amplía el alcance de la definición sosteniendo que "si, para simplificar el lenguaje, se designa con el término 'allegados' (allegados familiares, de grupo racial, de comunidad estatal) a los individuos que se encuentran en cierta relación, determinada por el orden jurídico, con el delincuente, responsabilizándolos por el delito de aquél, cabe determinar el delito como la conducta de aquel hombre contra quien, o contra cuyos allegados, se dirige la sanción como consecuencia" ${ }^{33}$. Pero esto presupone lo que hay que probar o responder: ¿Como se va a identificar al delincuente (y, por extensión, los "allegados" a él) sin un concepto de delito previamente determinado? ${ }^{34}$

Que Kelsen no ha logrado producir un criterio adecuado con el cual determinar el concepto de delito ha sido señalado por numerosos críticos $^{35}$. Creo que, al respecto, las críticas están absolutamente

\footnotetext{
${ }^{32}$ Id., ibid.

${ }^{33}$ Id., 129.

${ }^{34}$ Es posible, por otro lado, que varias conductas del delincuente aparezcan como condiciones del acto sancionatorio. Esto sucede siempre que la conducta que constituye el "delito" presupone lógicamente alguna otra conducta del mismo agente. Si no pagar un préstamo es un delito, será condición de la sanción que el préstamo haya sido percibido. Se ha tornado usual utilizar esto como argumento en contra de Kelsen, y sugerir que Kelsen "no se percató de esta dificultad". Pero esta acusación está errada. Kelsen explícitamente identifica el problema, y se esfuerza por resolverlo con su distinción entre "condiciones inmediatas" y "condiciones mediatas" de la sanción (estas últimas constituyen el "término final" de la imputación de la sanción del delito). Cfr. Teoría Pura del Derecho, cit., 107.

${ }^{35}$ Cf. H.L.A. Hart, "Kelsen Visited", in Essays in Jurisprudence and Philosophy, Oxford: Clarendon Pres (1983) 296ss.; Joseph Raz, The Concept of a Legal System, cit., 87-8, Carlos Santiago Nino, Introducción al Análisis del Derecho, $2^{\text {da }}$ ed., Buenos Aires: Astrea (1980) 177; Hugo R. Zuleta, "Ilícito", in El Derecho y la Justicia. Enciclopedia Ibero-Americana de Filosofía, vol. 11 (E. G. Valdés, F. J. Laporta, eds.), Madrid: Trotta (2001) 3389.
} 
justificadas. Resulta instructivo, sin embargo, investigar la causa de este error.

Una explicación usualmente propuesta es la siguiente: Kelsen no admitía, en su representación del sistema jurídico, normas de conducta dirigidas a los ciudadanos. Nino, por ejemplo, afirma que:

Es justamente la no inclusión de normas prohibitivas en su sistema lo que provoca el déficit que tiene Kelsen respecto al uso común para identificar al delito entre las condiciones de la sanción ${ }^{36}$.

También Zuleta dice que:

Los problemas que tiene Kelsen para aislar el acto ilícito sin recurrir a normas de carácter prohibitivo nos muestran que, después de todo, tal vez tales normas no sean superfluas, como él pensaba ${ }^{37}$.

Ambos por tanto parecen aceptar que, tal como lo expresa Alonso,

Kelsen sostiene que los sistemas jurídicos -en tanto órdenes coactivos- sólo se componen de normas primarias, considerando a las normas secundarias como superfluas ${ }^{38}$.

Esta lectura de la doctrina de Kelsen, si bien sumamente extendida, es sin embargo implausible incluso a nivel estrictamente hermenéutico. Veamos por qué. Cuando Kelsen emprende una delimitación de las "notas comunes" "de los sistemas sociales

\footnotetext{
${ }^{36}$ Carlos Santiago Nino, Introducción al Análisis del Derecho, cit., 183.

${ }^{37}$ Hugo R. Zuleta, “Ilícito”, cit., 340.

${ }^{38}$ Cf. pág. 24.
} 
designados como «derecho»[law, droit, diritto, etc.]"39, procede mediante una progresiva especificación a partir de un genus común. El derecho es definido como un "orden coactivo normativo", y así como especie o subconjunto del conjunto de órdenes normativos "que estatuyen sanciones". Este conjunto, a su vez, es un subconjunto del conjunto "sistemas sociales": órdenes normativos que regulan "el comportamiento humano en cuanto está en relación inmediata o mediata con otros hombres" ${ }^{40}$. El derecho se distingue de la moral no por ser un orden prescriptivo o de obligaciones, ni siquiera por ser un orden sancionatorio (dado que también el orden moral puede ser interpretado como un orden que provee sanciones) ${ }^{41}$, sino sólo por el modo en que prescribe:

No cabe reconocer una diferencia entre derecho y moral con respecto de qué sea lo que ambos órdenes sociales ordenan o prohíben, sino únicamente en cómo ellos obligan o prohíben una determinada conducta humana. El derecho sólo puede ser distinguido esencialmente de la moral cuando es concebido... como un orden coactivo; es decir, cuando el derecho es concebido como un orden normativo que trata de producir determinada conducta humana en cuanto enlaza a la conducta opuesta un acto coactivo socialmente organizado ${ }^{42}$.

El derecho, por tanto, es claramente presentado como un orden prescriptivo, como un orden de obligación:

La conducta que el sistema social requiere de un individuo es aquella a la cual ese individuo está obligado. En otras palabras, un individuo tiene la obligación de comportarse de determinada manera cuando esa conducta es requerida por el sistema social ${ }^{43}$.

\footnotetext{
39 Teoría Pura del Derecho, cit., 44, 46.

${ }^{40}$ Id., 38, 18.

${ }^{41}$ Id., 41-2.

${ }^{42}$ Id., 75.

${ }^{43}$ Id., 129.

100 - Revista Discusiones No 9
} 
La idea más común según la cual Kelsen consideraba que no hay en el derecho "normas de conducta" dirigidas a los ciudadanos (o, en una formulación afirmativa, que las normas jurídicas tienen como destinatarios únicamente a los funcionarios jurídicos) es incompatible con aquella caracterización. Es más, se opone frontalmente a afirmaciones muy claras de Kelsen, como la siguiente:

[C]uando una norma obliga a determinada conducta, y una segunda norma estatuye una sanción para el caso de no observancia de la primera, ambas se encuentran entrelazadas entre sí esencialmente. Ello sucede, especialmente, cuando un orden normativo -como un orden jurídico- obliga a una determinada conducta, justamente en cuanto enlaza a la conducta contraria un acto coactivo como sanción ${ }^{44}$.

Aquí tenemos dos normas -la norma de conducta y la norma de sanción- en una interconexión "esencial". Y esta conexión significa precisamente que ninguna de las dos normas es reducible a la otra. Por tanto, cuando Nino escribe que "según Kelsen, sólo es válida la afirmación de que el acto antijurídico es aquel al que una norma imputa una sanción, y no la relación inversa" ${ }^{45}$; o cuando Zuleta afirma que Kelsen "rechaza la idea de que la aplicación de una sanción es una consecuencia de la ilicitud de un acto, ya que esto supone que la noción de ilícito es independiente de la de «sanción»[; e]n su teoría, el concepto de «sanción» es previo"46 -esto es, cuando estos críticos reiteran la idea de que para Kelsen "sanción" es un término primitivo- están adscribiendo a Kelsen una posición contraria a la que él expresamente mantiene:

[L]a circunstancia de que determinada conducta humana sea convertida en condición de una sanción, en este sentido, equivale a decir que esa conducta se encuentra jurídicamente prohibida, es decir: que configura un acto antijurídico, que es un delito. Este concepto de sanción y el concepto de

\footnotetext{
${ }^{44}$ Id., 67.

${ }^{45}$ Carlos Santiago Nino, Introducción al Análisis del Derecho, cit., 175.

${ }^{46}$ Hugo R. Zuleta, "Ilícito”, cit., 337.
} 
antijuricidad se encuentran correlacionados. La sanción es la consecuencia de la antijuricidad; el acto antijurídico (o delito), una condición de la sanción ${ }^{47}$.

Bien por el contrario, la noción de Kelsen de delito depende de la admisión de normas de conducta dirigidas, por supuesto, a los ciudadanos. La visión del derecho como un orden prescriptivo (o, lo que es idéntico para Kelsen, como un orden imperativo $)^{48}$ presupone tanto el imperator cuanto el imperatus que es destinatario de las prescripciones $^{49}$. Kelsen ha expresamente refutado el mito contrario ${ }^{50}$; y de hecho hay en sus escritos muchos elementos para negarlo (incluso en la segunda edición de la Teoría Pura, en la cual el problema de los destinatarios de las normas no es expresamente tratado, y que, contrariamente a lo que sugiere Alonso en el inicio de la sección 1.2 de su artículo, no incluye mención alguna a la distinción entre normas "primarias" y "secundarias") ${ }^{51}$. Nada de esto, además, es inconsistente con la idea de que

Si un orden jurídico... contiene una norma que prescribe una determinada conducta y otra que enlaza al incumplimiento de

47 Teoría Pura del Derecho, cit., 53. Esto no colisiona con las famosa afirmación de que, en el derecho, "no hay mala in se, sino solamente mala prohibita" (id., 126). Esta afirmación expresa la noción (nada sorprendente en un autor positivista) de que cualquier conducta puede ser o no jurídicamente prohibida, y que una conducta puede ser considerada como delito si y sólo si ha sido jurídicamente prohibida: "desde el punto de vista de una teoría del derecho positivo, no hay hecho alguno que, en sí y de por sí" "sea un acto ilícito o delito" (id., ibid.).

${ }^{48}$ Id., 70, 84, 119.

${ }^{49}$ Id., 19 ss.

${ }^{50}$ Cf. Hans Kelsen, “Geltung und Wirksamkeit des Rechts' (publicado póstumamente en 2003, pero escrito probablemente alrededor de 1965), en Hans Kelsens stete Aktualität (R. Walter et al, eds.), Wien: Manz (2003), 12, n. 11. Hay traducción castellana: Hans Kelsen, Eugenio Bulygin, Robert Walter, Validez y Eficacia del Derecho, Buenos Aires: Astrea (2005) 61, n. 11.

${ }^{51}$ El primer ejemplo de una norma jurídica en la Teoría Pura es, de hecho, un ejemplo de una norma dirigida a los ciudadanos. Y son abundantes las referencias a "prohibiciones" jurídicas y al "acatamiento" o "infracción", por los ciudadanos, de las prescripciones que el derecho les endereza; y también al "delito" como conducta "contraria a una norma". 
la primera una sanción, la primera no constituye una norma independiente, sino que está esencialmente ligada a la segunda; ella determina sólo negativamente la condición a la que la segunda enlaza la sanción; y si la segunda determinara positivamente la condición a la cual ella enlaza la sanción, la primera sería, desde el punto de vista de la técnica legislativa, superflua $^{52}$.

De hecho, la razón misma por la cual Kelsen trata de resolver el problema de la determinación del concepto de "delito" reside precisamente en que él admite en su sistema la delimitación, en el conjunto de normas de sanción lato sensu, de un subconjunto de normas de sanción stricto sensu que implica la presuposición de normas de conducta dirigidas a los ciudadanos. En otras palabras: es precisamente porque admite las normas de conducta que Kelsen se ve forzado a buscar un criterio que le permita capturar, de entre el conjunto de "condiciones" de que depende una medida coercitiva, la condición constitutiva de la conducta "prohibida". Dada la correlatividad entre "delito" y sanción stricto sensu, le resulta indispensable la búsqueda de un criterio que permita seleccionar estas normas de sanción de entre las normas de sanción lato sensu.

En la terminología de Kelsen, como es bien conocido (y como apunta Alonso), las normas de sanción son llamadas "primarias", y las normas de conducta presupuestas por las primeras son "secundarias" 53 . También esto muestra que de ninguna manera Kelsen pretendía "reducir" una clase a la otra. Muestra, en otras palabras, que él admitía como distintas ambas clases de normas. Los adjetivos elegidos, además, son fácilmente explicables, aunque el punto es poco relevante: un vez

\footnotetext{
${ }^{52}$ Teoría Pura del Derecho, cit., 67, énfasis mío. Si esta idea es plausible o no constituye una cuestión diferente.

53 Esta terminología se ha tornado especialmente común despues de la publicación de General Theory of Law and State, Cambridge: Harvard University Press (1945) (ver esp. 61). Sin embargo, estaba ya presente en la primera edición de la Teoría Pura (1934); y, aunque, como ya se ha señalado, ausente de la segunda edición (1960), reaparece en la Teoría General de las Normas.
} 
que en el "pensamiento ingenuo" la sanción es entendida como una consecuencia de un delito que puede ser identificado independientemente del hecho de haber sido determinado jurídicamente como delito, los adjetivos de Kelsen están dirigidos a dejar en claro que el comportamiento delictivo es jurídicamente prohibido sólo porque una consecuencia sancionatoria es asociada a su realización. La norma sancionatoria es en este sentido la norma "primaria". La norma de conducta, aunque lógicamente prioritaria a una norma de sanción (que lógicamente la presupone), es "secundaria", ya que la determinación del delito no puede realizarse antes de que sea establecida la disposición sancionatoria que la prohíbe.

Una última observación importante a éste respecto. Las críticas mencionadas más arriba, como vimos, sugieren que el problema de Kelsen se hubiera resuelto admitiendo las normas de conducta, como si la estipulación de normas de conducta fuese una solución mágicamente suficiente para determinar el concepto de delito. Si, sin embargo, y como he tratado de mostrar, Kelsen admitía sin restricciones el carácter prescriptivo del derecho y las correspondientes normas de conducta, ¿no debería haber fácilmente determinado — si sus críticos tienen razón- el concepto de delito?

En realidad, como ahora podemos ver, el problema de Kelsen no es sólo el problema de Kelsen. Es más bien, en general, un problema para la teoría (i.e. para la "dogmática") penal, que tradicionalmente opera con normas de sanción formuladas del mismo modo. No resta duda que el problema es muy serio. No hay mejor testimonio de ello que las décadas de discusión entre penalistas, quienes no han alcanzado nunca un acuerdo cuando se trata de determinar cuáles condiciones del antecedente de la norma de sanción deberían ser tomadas como integrantes de la norma de conducta. Es usual, por ejemplo, distinguir entre "justificaciones" y "excusas" como elementos que excluyen la responsabilidad penal, y concebir a las primeras (pero no a las segundas) como delimitando el campo de la antijuridicidad. Esta distinción suele ser acompañada con la distinción entre "norma de valoración" (“Bewertungsnorm”) y "norma de determinación” (“Bestimmungsnorm”), 
donde la última -la genuina norma de conducta- abarcaría la ausencia de excusas. Pero todavía quedarían fuera de la denotación del término "delito", por ejemplo, hechos relativos a la posibilidad de persecución penal, a la competencia de la corte, etc., aunque cada uno de ellos sería, en el mismo sentido, una "condición" de la sentencia penal.

Al igual que Kelsen, las teorías penales afrontan este problema precisamente porque se basan en la distinción entre normas de conducta y normas de sanción. Es cierto que Kelsen no logró resolverlo. Pero tampoco las teorías penales lo han hecho hasta ahora. Y Kelsen, después de todo, resulta menos reprochable porque no hacía dogmática.

\section{4}

Las consideraciones precedentes nos permiten identificar dos errores fundamentales que Juan Pablo Alonso parece cometer en su artículo. Las "normas primarias" de sanción con que Alonso opera -y a partir de las cuales intenta "derivar" normas "secundarias" de conducta - toman en consideración las disposiciones características de las partes especiales de los Códigos Penales. Juan Pablo se ocupa de las "normas sancionatorias" de los arts. 176/3 y 302/1 del Código Penal argentino, que formula como: ${ }^{54}$

(NP 176/3) Si es un deudor sujeto a las reglas del concurso, declarado en quiebra, que paga una deuda por fuera de las reglas concursales, entonces es obligatorio imponer sanción penal de dos a seis años de prisión e inhabilitación especial de tres a diez años.

(NP 302/1) Si libró un cheque que fue rechazado sin fondos o sin autorización para girar en descubierto, y no lo paga dentro de 24 horas de intimado, entonces es obligatorio imponer sanción penal de seis meses a cuatro años de prisión e inhabilitación especial de uno a cinco años.

${ }^{54}$ Cf. págs. 27-28. 
De estas "normas" obtiene, por "derivación kelseniana", y respectivamente, los siguientes "deberes jurídicos" "secundarios":

(NS 176/3) Si es un deudor sujeto a las reglas del concurso entonces está prohibido -es obligatorio omitir- pagar por fuera de tales reglas.

(NS 302/1) Si libró un cheque rechazado sin fondos, y se encuentra intimado al pago, entonces es obligatorio pagar el cheque.

Parece, así, en primer lugar, que Juan Pablo Alonso intenta "derivar" deberes jurídicos a partir -no de las normas de sanción completamente articuladas, como debería haber hecho-, sino de las disposiciones en las cuales, en los códigos penales, y en sus palabras, se "enumeran diversas conductas susceptibles de sanciones penales" 55 . Este es el primer error fundamental del artículo de Juan Pablo. Alonso llama "normas primarias" a lo que expresan estas disposiciones, en las que suelen asociarse descripciones de comportamientos y sanciones aplicables (cf., v.g., toda su sección 2). Sin embargo, en ellas se indica solamente una de las condiciones de la sanción: la condición que en la dogmática penal suele recibir el nombre de "tipo objetivo" de una infracción criminal.

El segundo error es una consecuencia del primero. Es el error de entender que el contenido de un deber "derivado" es coincidente con el contenido del antecedente de la norma de sanción a partir de la cual se "deriva" el deber. Alonso, en otras palabras, parece sostener lo que yo arriba identifiqué como (TD*). Pero (TD*), como hemos visto, es indefendible. Y aunque sea verdad, como también señalé, que a veces se presenta la tesis de la "derivación" a partir de ejemplos simplificados y de formulaciones elípticas, hay que manejar ejemplos precisamente formulados cuando la tesis de la "derivación" sea esencial (como sucede en el trabajo de Alonso) para el research programme que se esté persiguiendo. En este caso, sin embargo, no es posible derivar

${ }^{55}$ Cf. pág.33-34.

106 - Revista Discusiones No 9 
(NS 176/3) y (NS 302/1) de las normas sancionatorias de los delitos de quiebra fraudulenta y de libramiento de cheques sin fondos.

Dicho de forma más precisa: como sugerí en la sección 2, podemos distinguir dos versiones de la tesis de que es posible derivar normas ("secundarias") de conducta a partir de normas ("primarias") de sanción. Estas versiones son (TD*) y (TD). El artículo de Juan Pablo Alonso está comprometido con alguna de estas versiones, ya que la presentación de su problema depende, como también hemos visto, de la "derivación" de "deberes jurídico penales" a partir de normas de sanción. Pero el siguiente dilema parece plantearse. Por un lado, si Alonso está efectivamente comprometido con (TD*), entonces está comprometido con una tesis que es claramente errada. Pero si, por otro lado, Alonso está en realidad comprometido solamente con (TD), entonces, aunque (TD) sea correcta, la tesis de la "derivación" no otorga a Alonso criterio alguno que le permita afirmar, como afirma, qué deberes se "derivan" de las normas de sanción de las infracciones de libramiento de cheques sin fondos y de quiebra fraudulenta. Es cierto que (NS 176/3) y (NS 302/1) no son formulaciones adecuadas de "deberes", ya que se limitan a recoger los elementos de los tipos penales correspondientes. Para delimitar y formular el contenido de los deberes cuya infracción es condición necesaria de que se haya practicado un delito criminal sería necesario tener en consideración, por lo menos, y como señalé en la sección precedente, los elementos relativos a la presencia o ausencia de causas de justificación, ya que una conducta justificada no está prohibida. En cualquiera de los casos el problema planteado por Juan Pablo se disuelve como un falso problema. Sin posibilidad de "derivar" de las normas de sanción relevantes los "deberes" que identifica como (NS 176/3) y (NS 302/1), pierde sentido la discusión de un supuesto "conflicto" entre tales "deberes" que resultaría de aquellas normas de sanción.

Debo quizás clarificar -aunque no matizar- estas últimas afirmaciones. Juan Pablo Alonso formula su problema con referencia a la matriz de lo que llama "sistema del ciudadano". En el caso (1) de este sistema, escribe Alonso, 
se trata de una persona sujeta a proceso concursal que libró un cheque sin provisión de fondos y que se encuentra intimado a su pago ${ }^{56}$.

Este caso -que, claro, es perfectamente posible- plantea dos cuestiones importantes, e interrelacionadas. Estas cuestiones, aunque no sean rigurosamente las que Alonso articula, subyacen a sus preocupaciones. La primera cuestión se formula del punto de vista de un sujeto colocado en aquella situación: lo que hay que saber es si debe o no pagar el cheque. La segunda cuestión se formula del punto de vista del juez, cuando tenga que decidir la responsabilidad de quien haya estado colocado en aquella situación -la posible responsabilidad por el delito de quiebra fraudulenta, en el caso (1) de la matriz del "sistema primario" ("deudor sujeto a las reglas de concurso que ha librado un cheque, luego rechazado sin fondos, y que paga el cheque dentro de las 24 horas de intimado" 57 ); o la posible responsabilidad por el delito de libramiento de cheques sin fondos, en el caso (2) de la misma matriz ("deudor sujeto a las reglas del concurso, que ha librado un cheque, luego rechazado sin fondos, y que no pagó el cheque dentro de las 24 horas de intimado" ${ }^{58}$ ). La respuesta a la primera pregunta va a condicionar la respuesta a la segunda.

Ambas preguntas generan, por cierto, alguna perplejidad. Pero se trata, estrictamente, de cuestiones de dogmática de la parte especial del derecho penal argentino. Han de discutirse, así, con argumentos de dogmática de la parte especial del derecho argentino. Mi punto es que es incorrecto presuponer -como presupone Alonso- que el problema sea un problema de "conflicto" o "contradicción normativa" entre "deberes jurídico penales", o que "el sistema secundario sujeta al agente a dos deberes jurídicos que no puede satisfacer simultáneamente" 59 . Lo único que puede afirmarse sin más es que cualquiera de los comportamientos realiza, y asimismo sólo prima facie, un tipo penal -y no que el agente,

\footnotetext{
${ }^{56}$ Cf. pág. 35.

${ }^{57}$ Cf. pág. 30.

${ }^{58}$ Cf. pág. 30.

${ }^{59}$ Cf. pág. 42.

108 - Revista Discusiones No 9
} 
necesariamente, "siempre violará algún deber jurídico"60, ni, mucho menos, que "haga lo que haga será sujeto a una sanción penal" "no tiene modo alguno de sustraerse de ser sancionado" 62 . Por la misma razón, es incorrecto caracterizar los casos (1) y (2) de la matriz del "sistema primario" diciendo que en el caso (1) "corresponde imponer una sanción penal (de 2 a 6 años de prisión e inhabilitación de 3 a 10 años) debido a que, al pagar por fuera de las reglas de concurso, [el deudor] violó la pars conditio creditorum" ${ }^{33}$; o diciendo que en el caso (2) "corresponde imponer una sanción penal (de 6 meses a 4 años de prisión e inhabilitación de 1 a 5 años) debido al no pago del cheque rechazado e intimado en tiempo y forma" ${ }^{4}$. Esto es errado: los casos (1) y (2) de la matriz del sistema primario incluyen solamente la descripción de los comportamientos típicos de cada infracción, y la realización de un tipo penal no es condición suficiente de la imposición de una sanción.

Puede ser que la discusión dogmática del problema conduzca a la conclusión de que la mejor caracterización del caso (1) del sistema secundario sea efectivamente la caracterización como "conflicto de deberes". Pero eso ha de ser el resultado de argumentos aducidos en la discusión del problema, y no el punto de partida del problema mismo. Porque puede también ser que el caso (1) no deba ser configurado como problema de "conflicto de deberes" (en el sentido en que en la dogmática penal este término suele ser utilizado), sino de otro modo cualquiera. Por ejemplo, como problema de delimitación de los tipos penales por medio de la inclusión de elementos implícitos en el tipo de una de las infracciones, o por medio de una interpretación adecuada del adjetivo "indebida" que, curiosamente, integra la descripción del tipo objetivo del delito de quiebra en el art. 176/3 del Código Penal argentino. Es evidente que para formular y discutir este problema dogmático uno no necesita de manipular cualquier tesis de teoría general del derecho relativa a la "noción" de deber jurídico, ni de comprometerse con

\footnotetext{
${ }^{60}$ Cf. pág. 40.

${ }^{61}$ Cf. pág. 40.

${ }^{62}$ Cf. pág. 42.

${ }^{63}$ Cf. pág. 30.

${ }^{64}$ Cf. pág. 30.
} 
cualquier tesis "kelseniana" sobre "derivación" de deberes. Además de innecesario -y, por eso, absolutamente dispensable- para la formulación y la discusión del problema que pretende discutir, el compromiso de Alonso con la idea de la "derivación kelseniana" de deberes es en realidad perjudicial para esa misma discusión, ya que restringe injustificadamente y a priori el catálogo de las posibles respuestas a las soluciones que la dogmática penal ha construido para tratar casos de conflicto de deberes propio sensu -soluciones propuestas en sede de justificación y de exculpación, y que así presuponen la verificación de la tipicidad penal objetiva y subjetiva de una conducta ${ }^{65}$. Pero una discusión completa de la cuestión necesitaría de argumentos de muchos otros tipos (además, creo, de una profundización de los propios argumentos que Alonso, en el marco de la discusión de su "conflicto de deberes", presenta de modo algo superficial ${ }^{66}$.

En el artículo de Juan Pablo Alonso -para resumir mis críticasun problema de dogmática penal surge travestido, o enmascarado, como un problema de teoría general del derecho. El problema de teoría del derecho, como he intentado mostrar, es un falso problema, basado en un entendimiento erróneo de la noción de "deber" jurídico. No es sorprendente, pues, que la cuestión dogmática subyacente, una vez incorrectamente planteada, no haya sido adecuadamente resuelta.

${ }^{65}$ Que esto es así lo muestra el modo como el propio Juan Pablo intenta solucionar la cuestión. Por ejemplo, la razón que ofrece en contra de la "condena bajo cualquier supuesto" es precisamente que "existiendo un conflicto de deberes" "deberá determinarse cuál de los deberes jurídicos es jerárquicamente superior; determinado ello, la condena solo sería factible bajo uno de los supuestos: puntualmente, bajo el supuesto de que infrinja el deber jurídico superior y se cumpla el inferior, siempre y cuando no se incurra en error al seleccionar entre los deberes jurídicos en conflicto" (cfr. pág. 49.) Incluso si se concuerda con Alonso en cuanto al modo de resolución de un conflicto de deberes, lo que habría de discutirse es, precisamente, si el problema es, o no, un problema de conflicto de deberes.

${ }^{66}$ Por ejemplo, discutiendo la importancia relativa de los "bienes jurídicos" protegidos por las dos incriminaciones, Juan Pablo concluye con excesiva rapidez que, existiendo "bienes jurídicos distintos que apuntan hacia principios distintos (la propiedad, por un lado; el libre mercado, por el otro"), "es difícil, sino imposible [!] determinar cuál de ellos debe prevalecer en desmedro del otro": cfr. pag.54. 